\title{
Synthesis, characterization and optical properties of zinc oxide nanoparticles
}

\author{
Surabhi Siva Kumar ${ }^{1 *}$, Putcha Venkateswarlu², Vanka Ranga Rao ${ }^{3}$ and Gollapalli Nageswara Rao ${ }^{4}$
}

\begin{abstract}
Zinc oxide nanoparticles were synthesized using a simple precipitation method with zinc sulfate and sodium hydroxide as starting materials. The synthesized sample was calcined at different temperatures for $2 \mathrm{~h}$. The samples were characterized by X-ray diffraction (XRD), scanning electron microscopy (SEM), energy dispersive spectroscopy (EDS), and proton-induced X-ray emission (PIXE) analysis. SEM images show various morphological changes of ZnO obtained by the above method. The average crystallite sizes of the samples were calculated from the full width at half maximum of XRD peaks by using Debye-Scherrer's formula and were found to be in the nanorange. EDS shows that the above route produced highly pure ZnO nanostructures. PIXE technique was used for trace elemental analysis of $\mathrm{ZnO}$. The optical band gaps of various $\mathrm{ZnO}$ powders were calculated from UV-visible diffuse reflectance spectroscopic studies.
\end{abstract}

Keywords: Nanostructures, Semiconductors, Chemical synthesis, Catalytic properties, Optical properties

\section{Background}

Nanosized particles of semiconductor materials have gained much more interest in recent years due to their desirable properties and applications in different areas such as catalysts [1], sensors [2], photoelectron devices $[3,4]$, highly functional and effective devices [5]. These nanomaterials have novel electronic, structural, and thermal properties which are of high scientific interests in basic and applied fields. Zinc oxide $(\mathrm{ZnO})$ is a wide band gap semiconductor with an energy gap of $3.37 \mathrm{eV}$ at room temperature. It has been used considerably for its catalytic, electrical, optoelectronic, and photochemical properties [6-9]. ZnO nanostructures have a great advantage to apply to a catalytic reaction process due to their large surface area and high catalytic activity [10]. Since zinc oxide shows different physical and chemical properties depending upon the morphology of nanostructures, not only various synthesis methods but also the physical and chemical properties of synthesized zinc oxide are to be investigated in terms of its morphology.

Many methods have been described in the literature for the production of $\mathrm{ZnO}$ nanostructures such as laser

\footnotetext{
* Correspondence: siva_ks9123@rediffmail.com

'Department of Chemistry, Anil Neerukonda Institute of Technology and

Sciences, Sangivalasa, Visakhapatnam 531 162, India

Full list of author information is available at the end of the article
}

ablation [11], hydrothermal methods [12], electrochemical depositions [13], sol-gel method [14], chemical vapor deposition [15], thermal decomposition [16], and combustion method $[17,18]$. Recently, $\mathrm{ZnO}$ nanoparticles were prepared by ultrasound [19], microwave-assisted combustion method [20], two-step mechanochemical-thermal synthesis [21], anodization [22], co-precipitation [23], and electrophoretic deposition [24].

Rodrigues-Paez et al. synthesized zinc oxide nanoparticles with different morphologies by controlling different parameters of the precipitation process such as solution concentration, $\mathrm{pH}$, and washing medium [25]. In the present study, $\mathrm{ZnO}$ nanostructures were synthesized using a simple precipitation method. Zinc sulfate heptahydrate and sodium hydroxide were used as precursors to formulate $\mathrm{ZnO}$ nanostructures. The prepared samples were characterized by X-ray diffraction (XRD) and scanning electron microscopy (SEM), and the purity of the sample was tested by energy dispersive spectroscopy (EDS) and proton-induced X-ray emission (PIXE) analysis. The band gap energies of the samples were calculated from diffuse reflectance spectroscopy. The morphology, crystallite size, and optical properties of $\mathrm{ZnO}$ nanostructures were investigated, and an attempt was made to correlate the optical properties of $\mathrm{ZnO}$ with morphology and crystallite size.

\section{实 Springer}




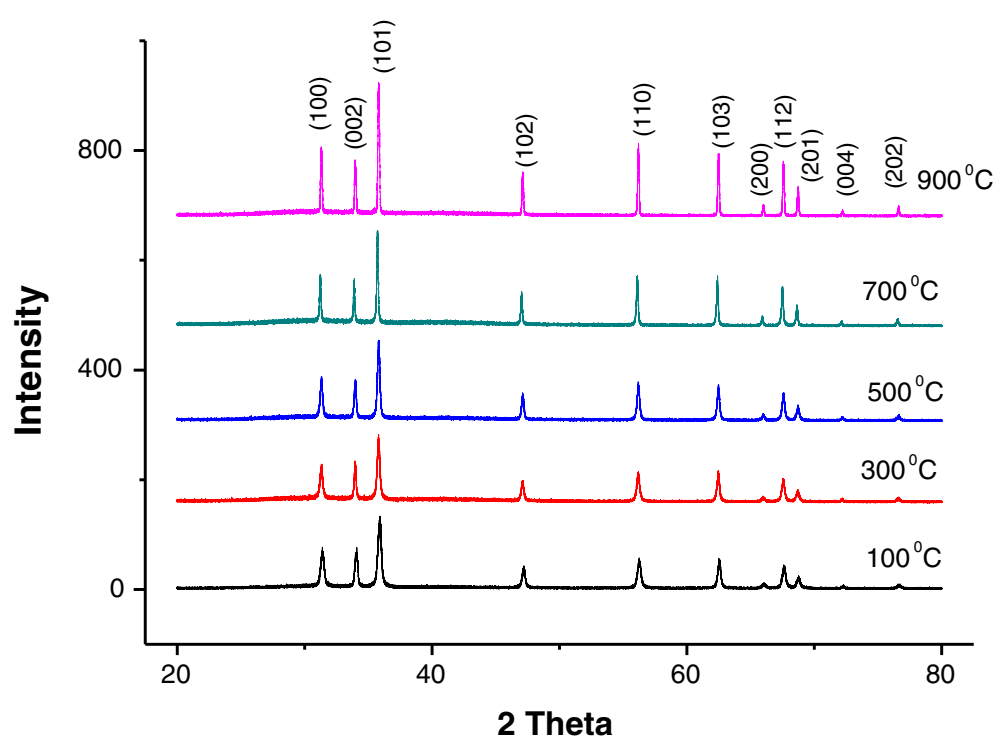

Figure 1 XRD patterns of ZnO-1 calcined at different temperatures.

\section{Methods}

\section{Materials}

Zinc sulfate heptahydrate and sodium hydroxide were used in the experiments. All the chemicals used were of analytical reagent grade obtained from Merck (Mumbai, India), and deionized water is used for the preparation of solutions.

\section{Synthesis of $\mathrm{ZnO}$}

To the aqueous solution of zinc sulfate, sodium hydroxide solution was added slowly dropwise in a molar ratio of $1: 2$ under vigorous stirring, and the stirring was continued for $12 \mathrm{~h}$. The precipitate obtained was filtered and washed thoroughly with deionized water. The precipitate was dried in an oven at $100^{\circ} \mathrm{C}$ and ground to fine powder using agate mortar [26]. The powder obtained from the above method was calcined at different temperatures such as $300^{\circ} \mathrm{C}, 500^{\circ} \mathrm{C}, 700^{\circ} \mathrm{C}$, and $900^{\circ} \mathrm{C}$ for $2 \mathrm{~h}$.

\section{Characterization}

\section{XRD and SEM}

The compounds were characterized for their structure and morphology by XRD and SEM. The XRD patterns of

Table 1 Average crystallite size of $\mathrm{ZnO}$ obtained from XRD using Equation 1

\begin{tabular}{cc}
\hline Calcination temperature $\left({ }^{\circ} \mathbf{C}\right)$ & Crystallite size, $\boldsymbol{D}(\mathbf{n m})$ \\
\hline 300 & 64 \\
500 & 74 \\
700 & 131 \\
900 & 187 \\
\hline
\end{tabular}

the powdered samples were recorded using a Bruker D8 Advanced X-ray diffractometer (Bruker Optik $\mathrm{GmbH}$, Ettlingen, Germany) with CuKa radiation $(\lambda=1.5418 \AA$, rated as $1.6 \mathrm{~kW}$ ), and SEM images of the samples were taken using a Philips XL 30 ESEM scanning electron microscope (FEI-Philips Company, Hillsboro).

\section{UV-vis diffuse reflectance spectroscopy}

UV-vis spectroscopy was used to characterize the optical absorption properties of $\mathrm{ZnO}$. The UV-vis absorption spectra of the samples were recorded in the wavelength range of 200 to $800 \mathrm{~nm}$ using a Shimadzu UV 3600 UV-vis-NIR spectrometer (Shimadzu Corporation, Kyoto, Japan) in diffuse reflectance mode using $\mathrm{BaSO}_{4}$ as reference. Spectra were recorded at room temperature, and the data were transformed through the Kubelka-Munk function [27].

\section{Proton-induced X-ray emission}

Finely powdered samples were mixed with pure graphite in the ratio of 1:1 (150 $\mathrm{mg}$ each), homogenized, and pressed into a 13-mm-diameter pellet. PIXE measurements have been carried out on a 3-MV horizontal pelletron accelerator at the Institute of Physics, Bhubaneswar [28]. Proton beam was collimated to a diameter of $3 \mathrm{~mm}$ on the target. A $\mathrm{Si}(\mathrm{Li})$ detector was kept at $90^{\circ}$ with respect to the beam direction. The detector has an active area of $30 \mathrm{~mm}^{2}$ with a beryllium window having a thickness of $12 \mu \mathrm{m}$ and an energy resolution of $170 \mathrm{eV}$ at $5.9 \mathrm{keV}$. Integrated charge on the sample was measured using a current integrator, which was connected to the target holder. The X-rays coming out of the chamber 


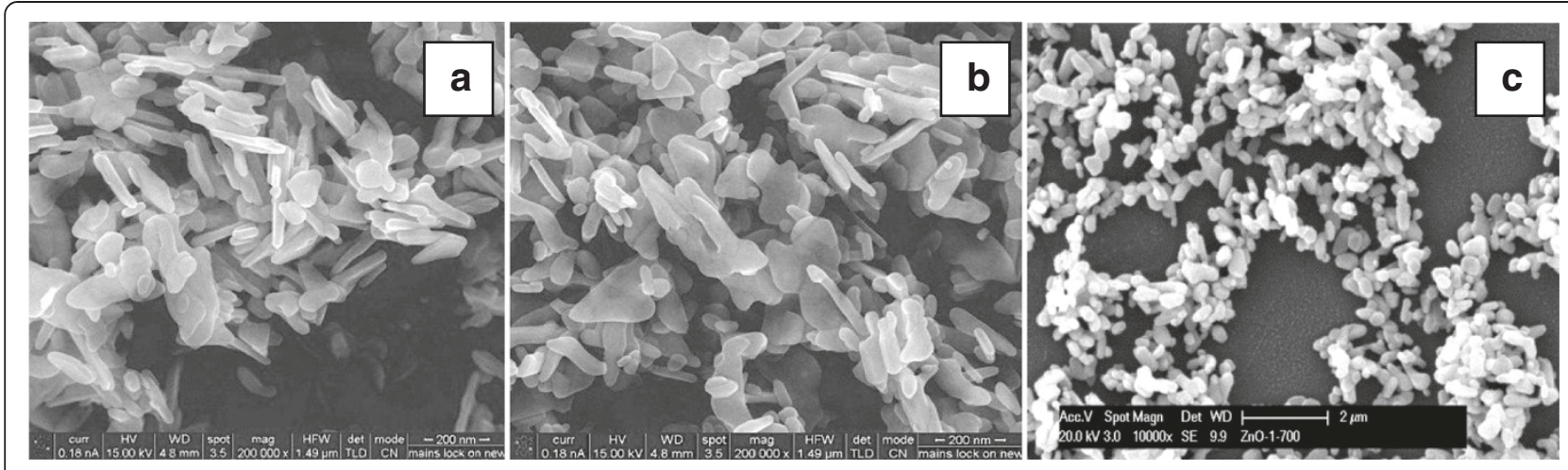

Figure 2 SEM images of $\mathrm{ZnO}$ samples calcined at three different temperatures. (a) $300^{\circ} \mathrm{C},(\mathbf{b}) 500^{\circ} \mathrm{C}$, and $(\mathbf{c}) 700^{\circ} \mathrm{C}$.

through a 95- $\mu \mathrm{m}$ Mylar window traveled through an air gap of $4 \mathrm{~cm}$ before entering the $\mathrm{Si}(\mathrm{Li})$ detector.

The targets were kept in the PIXE chamber at $45^{\circ}$ to the beam. The $\mathrm{Si}(\mathrm{Li})$ detector is placed at $90^{\circ}$ to the beam, and the beam current was kept in the range of 3 to $10 \mathrm{nA}$. Spectra were recorded using a Canberra MCA [29] (Canberra Industries, Meriden, CT, USA) and were transferred to a personal computer [30].

PIXE spectral analyses were carried out using GUPIX-95 [31] software that provides nonlinear least-square fitting of the spectrum. The thick-target PIXE analysis was performed since the target was thick enough to stop the proton beam entirely. To check the adopted analysis procedure and input parameters, external standard method was adopted using the macrometer standards and other certified reference materials, and accordingly, the values were normalized. Further details about the analysis procedure can be obtained from our earlier references $[28,29]$.

\section{Results and discussion}

Catalyst characterization

$X R D$ analysis

The XRD patterns of the $\mathrm{ZnO}$ powders prepared by the above method and calcined at different temperatures are shown in Figure 1. All the diffraction peaks are well indexed to the hexagonal $\mathrm{ZnO}$ wurtzite structure (JCPDS no. 36-1451). Diffraction peaks corresponding to the impurity were not found in the XRD patterns, confirming the high purity of the synthesized products. The intensity of the peaks increases with calcination temperature, indicating increased crystallinity. A definite line broadening of diffraction peaks at $300^{\circ} \mathrm{C}, 500^{\circ} \mathrm{C}$, and $700^{\circ} \mathrm{C}$ indicates that the synthesized materials are in the nanometer range. Table 1 shows the average crystallite sizes of the samples calculated by Debye-Scherrer's equation (Equation 1) using the full width at half maximum of 100, 002, and 101 of the X-ray diffraction peaks [32]. The average crystallite size increases with increase in calcination temperature. A significant increase in crystallite size is observed for the sample calcined at $900^{\circ} \mathrm{C}$. At such high temperatures, migration of grain boundaries occurs, causing the coalescence of small grains and formation of large grains.

$$
D=\frac{0.89 \lambda}{\beta \cos \theta}
$$

where $D$ is the crystallite size $(\mathrm{nm}), \lambda$ is the wavelength

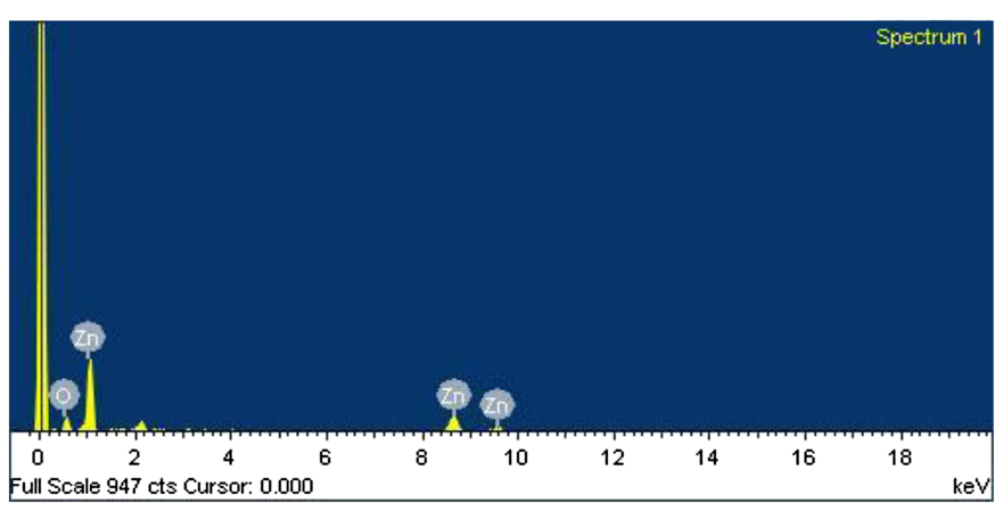

Figure 3 Energy dispersive spectra of $\mathrm{ZnO}$ calcined at $500^{\circ} \mathrm{C}$. 


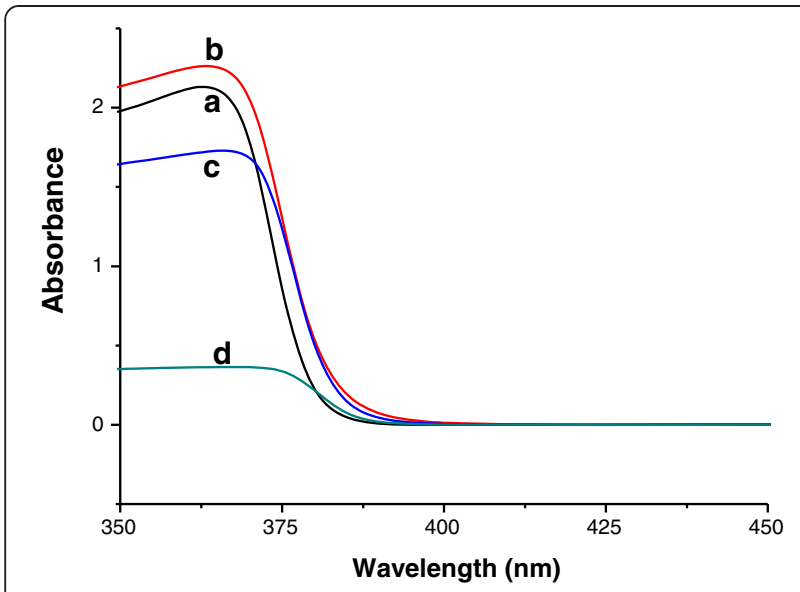

Figure $4 \mathrm{UV}$-vis absorption spectra of $\mathrm{ZnO}$ calcined at various temperatures. (a) $300^{\circ} \mathrm{C}$, (b) $500^{\circ} \mathrm{C}$, (c) $700^{\circ} \mathrm{C}$, and (d) $900^{\circ} \mathrm{C}$.

of incident X-ray ( $\mathrm{nm}), \beta$ is the full width at half maximum, and $\theta$ is the diffraction angle.

\section{SEM and EDS analysis}

The SEM images of the samples are shown in Figure 2. The morphologies of $\mathrm{ZnO}$ are changed with calcination temperature. The samples calcined at $300^{\circ} \mathrm{C}$ and $500^{\circ} \mathrm{C}$ are nanoflakes which are turned to particles when calcined at $700^{\circ} \mathrm{C}$. The SEM images of $\mathrm{ZnO}$ samples show that the agglomerations of particles are much less in this method of preparation. High-resolution SEM images of $\mathrm{ZnO}$ calcined at $300^{\circ} \mathrm{C}$ and $500^{\circ} \mathrm{C}$ (Figure 2b) show the presence of nanoparticles. The energy dispersive spectra of the samples obtained from the SEM-EDS analysis (Figure 3) clearly show that the sample prepared by the above route has pure $\mathrm{ZnO}$ phases.

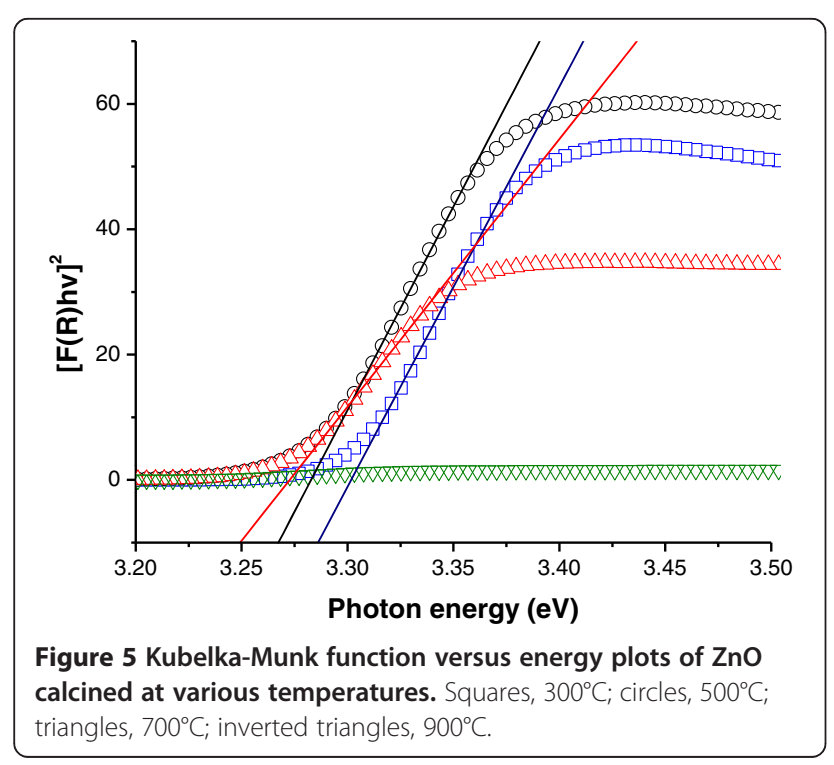

Table 2 Optical band gap of different $\mathrm{ZnO}$ samples calcined at different temperatures

\begin{tabular}{cc}
\hline Calcination temperature $\left({ }^{\circ} \mathrm{C}\right)$ & Band gap $(\mathrm{eV})$ \\
\hline 300 & 3.30 \\
500 & 3.28 \\
700 & 3.27 \\
\hline
\end{tabular}

\section{Diffuse reflectance analysis}

The UV-visible absorption spectra of the samples are shown in Figure 4. All the samples have a strong absorption maximum below $400 \mathrm{~nm}$. The absorption maximum of the samples calcined at $500^{\circ} \mathrm{C}$ and $700^{\circ} \mathrm{C}$ are shifted to higher wavelengths. This red shift can be attributed to the agglomerations in the samples [33]. The band gap energy of the samples are measured by the extrapolation of the linear portion of the graph between the modified Kubelka-Munk function $[F(R) h v]^{2}$ versus photon energy $(h v)$ [27], as shown in Figure 5. The samples calcined at $900^{\circ} \mathrm{C}$ have low reflectance, and it is difficult to calculate the band gap of these samples. The band gap of $\mathrm{ZnO}$ is decreased with an increase in calcination temperature. This is due to the increase in particle size of $\mathrm{ZnO}$ with calcination temperature. The band gaps of the samples are shown in Table 2.

\section{PIXE analysis}

The samples are analyzed using GUPIX software for the purity and trace elements present in the $\mathrm{ZnO}$ nanoparticles. The results shown in Table 3 indicate that the prepared $\mathrm{ZnO}$ nanoparticles are having $99.7 \%$ purity with contaminants like $\mathrm{Fe}$ and $\mathrm{Ti}$ at trace level. The PIXE spectrum of the $\mathrm{ZnO}$ nanoparticle calcined at $300^{\circ} \mathrm{C}$ (Figure 6) reflects the dominated characteristic peak of $\mathrm{Zn}$. However, the pile-up continuum may contain the characteristic X-ray lines of the trace contaminants like $\mathrm{Pb}$ which cannot be observed in the spectra and could not be estimated due to increase in the minimum detection limit of the respective elements. The importance of effective suppression of the pile-up continuum is obvious in terms of the limit of detection of trace level contaminants. The pile-up continuum of major elements like $\mathrm{Zn}$ in this case may overlap the $\mathrm{X}$-ray lines of trace elements; therefore, the limits of detection for those elements are worse. However, as the residual concentration is only within some thousands of

Table 3 Concentration of various elements in $\mathrm{ZnO}$ nanoparticles

\begin{tabular}{ccc}
\hline Element & Concentration & Statistical error (\%) \\
\hline $\mathrm{Ti}$ & $1,000 \mathrm{ppm}$ & 11 \\
$\mathrm{Fe}$ & $900 \mathrm{ppm}$ & 15 \\
$\mathrm{Zn}$ & $99.70 \%$ & 0.1 \\
\hline
\end{tabular}




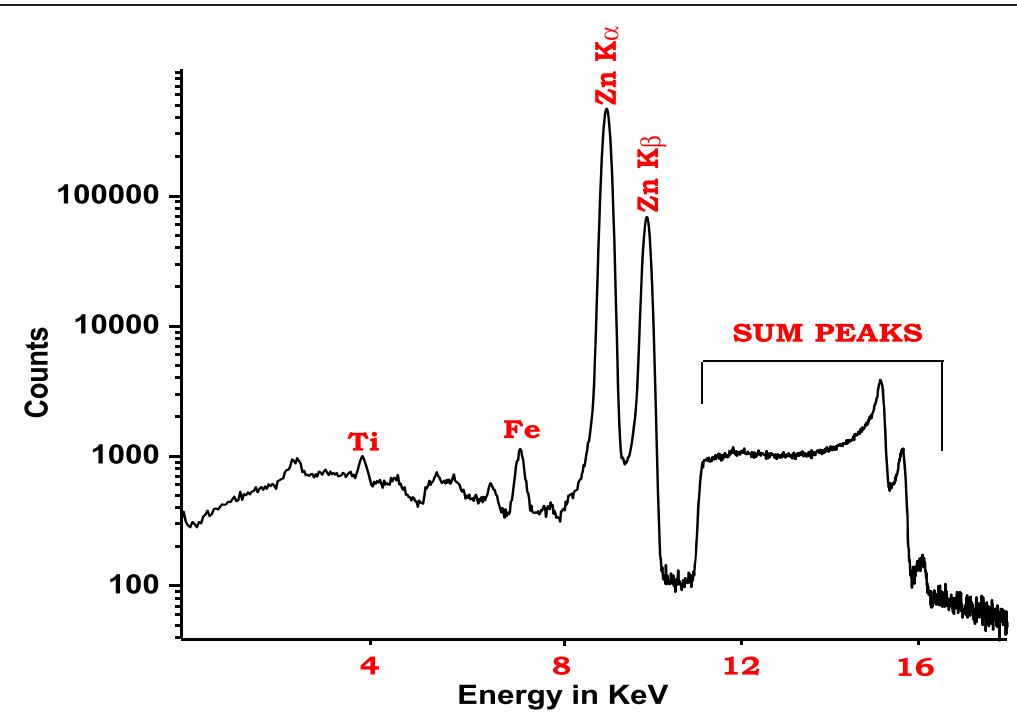

Figure 6 PIXE spectrum of $\mathrm{ZnO}$ calcined at $300^{\circ} \mathrm{C}$.

parts per million, these individual elements must be much less in concentration if present and hence may not affect the purity of materials significantly. So, the PIXE study confirms the effectiveness of our nanoparticle preparation procedure.

\section{Conclusions}

$\mathrm{ZnO}$ nanoparticles were prepared using a simple precipitation method. The XRD and EDS analyses clearly indicate that highly pure $\mathrm{ZnO}$ is formed in the above method. SEM images of $\mathrm{ZnO}$ show that the morphology was changed with calcination temperature. PIXE analysis confirmed that the prepared material has a high purity and the presence of elements like $\mathrm{Fe}$ and $\mathrm{Ti}$ in trace level. The band gap of $\mathrm{ZnO}$ was decreased by an increase in calcination temperature, and the absorption maximum is also shifted to higher wavelengths.

\section{Competing interests}

The authors declare that they have no competing interests.

\section{Authors' contributions}

SS was involved in the acquisition, analysis, and interpretation of data. PV was involved in getting the PIXE data and analysis. VR was involved in designing the experimental work and drafting the manuscript. GN revised the manuscript critically and gave final approval for submission. All authors read and approved the final manuscript.

\section{Acknowledgment}

SSK is indebted to the UGC Networking program, University of Hyderabad for providing instrumental facility to carry out the XRD and SEM analyses. The authors are thankful to the Institute of Physics for giving permission to carry out the PIXE analysis.

\section{Author details}

'Department of Chemistry, Anil Neerukonda Institute of Technology and Sciences, Sangivalasa, Visakhapatnam 531 162, India. ²Department of Physics, Anil Neerukonda Institute of Technology and Sciences, Sangivalasa, Visakhapatnam 531 162, India. ${ }^{3}$ Department of Chemistry, Government
College (Autonomous), Rajahmundry 533 105, India. ${ }^{4}$ School of Chemistry, Andhra University, Visakhapatnam 530 003, India.

Received: 9 September 2012 Accepted: 28 April 2013

Published: 7 May 2013

\section{References}

1. Joshi, SS, Patil, PR, Naimase, MS, Bakare, PP: Role of ligands in the formation, phase stabilization, structural and magnetic properties of a- $\mathrm{Fe}_{2} \mathrm{O}_{3}$ nanoparticles. J. Nanopart. Res. 5, 635-643 (2006)

2. Cheng, XL, Zhao, H, Huo, LH, Gao, S, Zhao, JG: ZnO nanoparticulate thin film: preparation, characterization and gas-sensing properties. Sens. Actuators B. 102, 248-252 (2004)

3. Lee, SY, Shim, ES, Kang, HS, Pang, SS: Fabrication of ZnO thin film diode using laser annealing. Thin Solid Films. 437, 31-34 (2005)

4. Wang, ZL, Kong, XY, Ding, Y, Gao, P, Hughes, WL: Semiconducting and piezoelectric oxide nanostructures induced by polar surfaces. Adv. Funct. Mater. 14, 943-956 (2004)

5. Huang, YH, Zang, Y, Liu, L, Fan, SS, Wei, Y, He, J: Controlled synthesis and field emission properties of $\mathrm{ZnO}$ nanostructures with different morphologies. J. Nanosci. Nanotechnol. 6, 787-790 (2006)

6. Brida, D, Fortunato, E, Ferreira, I, Aguas, H, Martins, R: New insights on large area flexible position sensitive detectors. J. Non-Cryst. Solids. 299, 1272-1276 (2002)

7. Wang, ZL: Zinc oxide nanostructures: growth properties and applications. J. Phys. Condens. Matter. 16, R829-R858 (2004)

8. Suchea, M, Christoulakis, S, Moschovis, K, Katsarakis, N, Kiriakidis, G: ZnO transparent thin films for gas sensor applications. Thin Solid Films. 515, 551-554 (2006)

9. Ashour, A, Kaid, MA, El-Syed, NZ, Ibrahim, AA: Physical properties of ZnO thin films deposited by spray pyrolysis technique. Appl. Surf. Sci. 252, 7844-7848 (2006)

10. Chen, JC, Tang, CT: Preparation and application of granular $\mathrm{ZnO} / \mathrm{Al}_{2} \mathrm{O}_{3}$ catalyst for the removal of hazardous trichloroethylene. J. Hazard. Mater. $142,88-96$ (2007)

11. Scarisoreanu, N, Metai, DG, Dinescu, G, Epurescu, G, Ghica, C, Nistor, LC, Dinescu, M: Properties of $\mathrm{ZnO}$ thin films prepared by radio-frequency plasma beam assisted laser ablation. Appl. Surf. Sci. 247, 518-525 (2005)

12. $\mathrm{Ni}, \mathrm{YH}, \mathrm{Wei}, \mathrm{XW}$, Hong, JM, Ye, Y: Hydrothermal synthesis and optical properties of $\mathrm{ZnO}$ nanorods. Mater. Sci. Eng., B, Solid State Mater. Adv. Technol 121, 42-47 (2005)

13. Chang, S, Yoon, SO, Park, HJ, Sakai, A: Luminescence properties of Zn nanowires prepared by electrochemical etching. Mater. Lett. 53, 432-436 (2002)

14. Ristiac, M, Musiac, S, Ivanda, M, Popoviac, S: Sol-gel synthesis and characterization of nanocrystalline $\mathrm{ZnO}$ powders. J. Alloys Compd. 397 L1-L4 (2005) 
15. $\mathrm{Wu}, \mathrm{J}$, Liu, SC: Low-temperature growth of well-aligned $\mathrm{ZnO}$ nanorods by chemical vapor deposition. Adv. Mater. 14, 215-218 (2002)

16. Wang, RC, Tsai, CC: Efficient synthesis of $\mathrm{ZnO}$ nanoparticles, nanowalls, and nanowires by thermal decomposition of zinc acetate at a low temperature. Appl. Phys. A. 94, 241-245 (2009)

17. Lamas, DG, Lascalea, GE, Walsoc, NE: Synthesis and characterization of nanocrystalline powders for partially stabilized zirconia ceramics. J. Eur. Ceram. Soc. 18, 1217-1221 (1998)

18. Badhuri, $\mathrm{S}$, Badhuri, SB: Enhanced low temperature toughness of $\mathrm{Al}_{2} \mathrm{O}_{3}-\mathrm{ZrO}_{2}$ nano/nano composites. Nanostrct. Mater. 8, 755-763 (1997)

19. Khorsand, Z, Abid, A, Majid, WH, Wang, HZ, Yousefi, R, Golsheikh, M, Ren, ZF: Sonochemical synthesis of hierarchical ZnO nanostructures. Ultrasonic Sonochemistry 20, 395-400 (2013)

20. Kooti, M, Nagdhi Sedish, A: Microwave-assisted combustion synthesis of ZnO nanoparticles. J. Chem (2013). doi:10.1155/2013/562028

21. Rajesh, D, Vara Lakshmi, B, Sunandana, CS: Two-step synthesis and characterization of $\mathrm{ZnO}$ nanoparticles. Physica B-Cond. Mater. 407 4537-4539 (2012)

22. Shetty, A, Nanda, K: Synthesis of zinc oxide porous structures by anodisation with water as an electrolyte. Appl. Phys. A. 109, 151-157 (2012)

23. Singh, O, Kohli, N, Singh, RC: Precursor controlled morphology of zinc oxide and its sensing behavior. Sens. Actuators B. 178, 149-154 (2013)

24. Vazquez, A, Lopez, IA, Gomez, I: Growth mechanism of one-dimensional zinc sulfide nanostructures through electrophoretic deposition. J. Mater. Sci 48, 2701-2704 (2013)

25. Rodrigues-Paez, J, Caballero, AC, Villegas, M, Moure, C, Duran, P, Fernandz, JF: Controlled precipitation methods: formation mechanism of $\mathrm{ZnO}$ nanoparticles. J. Eur. Ceram. Soc. 21, 925-930 (2001)

26. Daneshvar, N, Aber, S, Sayed Dorraji, MS, Khataee, AR, Rasoulifard, MH: Preparation and investigation of photocatalytic properties of $\mathrm{ZnO}$ nanocrystals: effect of operational parameters and kinetic study. Int. J. Chem. Biom. Eng 1(1), 24-29 (2008)

27. Cimitan, S, Albonetti, S, Forni, L, Peri, F, Lazzari, D: Solvothermal synthesis and properties control of doped $\mathrm{ZnO}$ nanoparticles. J. Colloid. Interface Sci. 329, 73-80 (2009)

28. Vijayan, V, Ramamurthy, VS, Behera, SN, Puri, S, Shanti, JS, Singh, N: Elemental composition of fly ash from a coal fired thermal power plant: a study using PIXE and EDXRF. X-ray spectrometry. 26, 65-68 (1997)

29. Vijayan, V, Nayak, PK, Chakrovortty, V: Proton induced X-ray emission studies on Indian copper coins. Ind. J. Phys. A. 76, 477-479 (2002)

30. Maxwell, JA, Teesdale, WJ, Campbell, JL: The Guelph PIXE software package II. Nucl. Instrum. Methods B. 95, 407-421 (1995)

31. Gleiter, H: Nanocrystalline materials. Prog. Mater. Sci. 33, 223-315 (1989)

32. Chen, CC, Liu, P, Lu, CH: Synthesis and characterization of nano-sized ZnO powders by direct precipitation method. Chem. Eng. J. 144, 509-513 (2008)

33. Babita, B, Kishore Kumar, D, Manorama, SV: Hydrothermal synthesis of highly crystalline ZnO nanoparticles: a competitive sensor for $\mathrm{LPG}$ and EtOH. Sens. Actuators B. 119, 676-682 (2006)

doi:10.1186/2228-5326-3-30

Cite this article as: Kumar et al: Synthesis, characterization and optical properties of zinc oxide nanoparticles. International Nano Letters 2013

\section{Submit your manuscript to a SpringerOpen ${ }^{\circ}$ journal and benefit from:}

- Convenient online submission

- Rigorous peer review

- Immediate publication on acceptance

- Open access: articles freely available online

- High visibility within the field

- Retaining the copyright to your article

Submit your next manuscript at $\gg$ springeropen.com 